\title{
DESENVOLVIMENTO URBANO SUSTENTÁVEL - BAIRRO HAMMARBY SJÖSTAD, ESTOCOLMO
}

\section{SUSTAINABLE URBAN DEVELOPMENT - HAMMARBY SJÖSTAD NEIGHBORHOOD, STOCKHOLM}

\author{
Veronica R Polzer
}

\author{
Universidade Mackenzie, Edifício João Calvino, Rua da Consolação, 930, \\ Consolação, São Paulo, SP. E-mail: vpolzer@yahoo.com.br
}

\begin{abstract}
RESUMO
Hammarby Sjöstad é um bairro localizado ao sul da cidade de Estocolmo. Considerado um dos bairros mais sustentáveis do mundo, servindo de modelo não só para as cidades suecas e para o conceito Symbiocity, mas para todos os demais centros urbanos. Construído numa área portuária e industrial o bairro transformou e revitalizou não só o local de implantação, mas todo o seu entorno. A meta foi construir um novo bairro cujo impacto ambiental fosse $50 \%$ inferior comparado às construções anteriores do local. Para isso foram utilizados métodos construtivos eficientes e com menor desperdício, utilizando materiais locais e de reuso. $\mathrm{O}$ bairro oferece ainda tratamento de água e esgoto no local, coleta de resíduos sólidos pneumática, sistema de transporte coletivo conectado ao existente, amplas áreas verdes com mobiliário urbano, calçadas e ciclovias integrando todos os espaços. A qualidade de vida da população e o respeito ao meio ambiente foram os fatores determinantes que permitiram tornar o local um centro de referência no quesito sustentabilidade.

Palavras-chave: Desenvolvimento urbano sustentável. Hammarby Sjöstad. SymbioCity. Gerenciamento de resíduos sólidos.

ABSTRACT

Hammarby Sjöstad is a district located in the south of Stockholm. It is considered one of the most sustainable neighbourhoods in the world, serving as a model not only for the Swedish cities and the SymbioCity concept but also for all other urban centres. The neighbourhood was built in a port and industrial area and its construction was responsible for transforming and revitalizing not only the site of implantation but all its surroundings. The goal was to build a new neighbourhood whose environmental impact was $50 \%$ lower compared to the previous construction site. To this effect, efficient construction methods were used, considering less production of waste and the use and reuse of local materials. The neighbourhood also offers water and sewage treatment on site, pneumatic solid waste collection, and public transportation connected to the existing system, large green areas with urban equipment, sidewalks and bike paths integrating all spaces. The population's quality of life and the respect for the environment were the key factors that allowed make the place a centre of excellence in the category of sustainability.
\end{abstract}

Keywords: Sustainable urban development. Hammarby Sjöstad. SymbioCity. Solid waste management. 


\section{INTRODUÇÃO}

Estocolmo é a capital e a cidade mais populosa da Suécia, com cerca de 900.000 habitantes, e 2.2 milhões em sua área metropolitana, abrigando $21 \%$ da população total. É constituída geograficamente por 14 ilhas, localizadas no lago Mälaren, que se conectam através de 53 pontes. O arquipélago da grande Estocolmo possui mais de 30.000 ilhas distribuídas ao longo do lago Mälaren até o mar Báltico. É considerada uma cidade recente comparada aos demais municípios suecos e foi fundada em 1252 para servir de base militar, protegendo a região das invasões e por fim tornou-se centro de comércio entre as cidades próximas. É conhecida mundialmente por ser uma das cidades mais habitáveis do mundo, extremamente segura, limpa, planejada e organizada do ponto de vista urbanístico (STOCKHOLM, 2014).

A Suécia é conhecida também por suas regulamentações ambientais rigorosas que estão acima das metas estabelecidas pela União Europeia, de forma que a cidade de Estocolmo, a mais importante do país, seja palco de intervenções e avanços tecnológicos visando minimizar os impactos ambientais criados pelos edifícios e demais atividades desenvolvidas nas cidades. Além disso, Estocolmo foi a primeira cidade a ganhar o título de Capital Europeia mais verde em 2010 (STOCKHOLM, 2014). O surgimento do novo bairro Hammarby Sjöstad foi uma dessas experiências bem sucedidas que agregou em seu planejamento urbano, construção de edifícios modernos e sustentáveis, aproveitamento dos recursos naturais, reuso e tratamento da água e eficiência energética.

Segundo Wells (2014) a Suécia tem como diferencial o respeito pelo próximo e pelos interesses comuns, trabalhando as expectativas por meio do diálogo e da colaboração, estabelecendo uma cultura de confiança entre todos e formalizando as expectativas através de acordos legais. Esse é o sistema sueco de resolver os problemas locais e trabalhar de forma integrada para alcançar os objetivos. Se todos acreditarem e trabalharem juntos terão mais chances de obter sucesso.

Cada município necessita elaborar um plano de zoneamento em longo prazo (översiktsplan) prevendo como será a expansão da cidade, localizando as áreas de moradia, trabalho e estudo. Nos últimos 25 anos a tendência foi adensar as áreas construídas, especialmente mais próximas aos centros urbanos e revitalizar áreas degradadas como zonas industriais e portuárias. As grandes cidades como Estocolmo, Göteborg e Malmö estão evitando o espraiamento, buscando soluções de adensamento e melhorando também a infraestrutura existente.

Depois de estabelecido o uso do solo em longo prazo, os municípios desenvolvem o plano detalhado (detaljplan), com as estratégias para cada bairro e isso inclui a especificação de: número de andares dos edifícios, sua posição no lote, recuos, orientação solar, a relação do edifício com as calçadas, ruas e ciclovias, a localização dos acessos, os locais de espaços abertos, os caminhos para pedestre e seu paisagismo, as áreas verdes, os locais para bicicletários, as cores aceitas para as fachadas e os materiais a serem utilizados na construção.

Para estabelecer esses padrões normalmente um grupo de arquitetos da própria prefeitura ou através de um concurso público é quem determina o projeto e os estudos a serem submetidos à aprovação das autoridades. Parte do projeto é dedicada às questões ambientais, que inclui os corredores verdes, áreas permeáveis, edifícios energeticamente eficientes, gestão e infraestrutura de resíduos sólidos e água (WELLS, 2014).

O bairro de Hammarby Sjöstad, em Estocolmo, foi motivo de muitas discussões desde a década de 1980 quando a área foi disponibilizada para uso industrial e para armazenagem. Pequenas indústrias se estabeleceram no local, mas também alguns assentamentos precários de uso temporário, degradando ainda mais o ambiente. Em 1996 o governo municipal reuniu as principais empresas de infraestrutura (energia, água e resíduos) para apresentar o projeto para um novo bairro e solicitar destas empresas soluções sustentáveis de maneira integrada. 
Esse processo alavancou uma nova maneira de resolver os problemas da cidade de forma holística, pois as empresas não foram convocadas separadamente, mas sim convidadas a trabalharem juntas nas soluções. A primeira proposta apresentada pelas empresas foi rejeitada pelo governo que alegou que necessitava de soluções mais inovadoras.

No começo de 1997 vários encontros e workshops aconteceram, de forma que outras empresas pudessem participar e ajudar na implantação de novas tecnologias e ideias. Foram criados vários modelos até chegar num único que integrasse os 3 eixos principais: água, energia e resíduos. As empresas apresentaram um projeto que utilizava parte do sistema existente e parte com inovações e tecnologias atuais.

Em relação às inovações, foi sugerido incluir no projeto: estações separadas de tratamento de águas servidas, água de chuva e esgoto; aquecimento solar de água somado ao sistema de aquecimento existente; implantação de painéis fotovoltaicos para geração de energia; aumentar a utilização do biogás para transporte e para abastecimento de fogões a gás; e sistema de coleta de resíduos sólidos à vácuo, eliminando a coleta por caminhões.

Em 1998, os edifícios foram então demolidos e iniciou-se a construção do novo bairro que deverá ser concluído em 2018. Além disso, havia a intenção de utilizar o bairro para sediar os jogos das Olimpíadas de 2004. Naquele momento, no meio dos anos 1990, foram revisitadas as metas ambientais que estavam sendo utilizadas nas Olimpíadas de Sydney de 2000. Estocolmo não foi sede das Olimpíadas em 2004, mas a construção do bairro continuou com os mesmos parâmetros ambientais que haviam sido estabelecidos até se tornar um caso de estudo internacional (IVEROTH et al., 2013).

O bairro novo é relativamente próximo ao centro de Estocolmo, localizado a cerca de $6 \mathrm{~km}$ da estação central, que conecta as principais linhas de trem e metrô do município. Constituindo uma área de expansão natural da cidade o que atraiu ainda mais a atenção para a sua revitalização e nova ocupação. Além disso, todo o traçado do bairro, infraestrutura e arquitetura foram pensados considerando a conexão com as áreas existentes e o crescimento previsto da cidade até 2030. Foi considerado o maior e mais longo projeto urbanístico por muitos anos e envolveu não só Estocolmo mas também a cidade de Nacka, que faz divisa ao bairro. Ambos os municípios estudaram a melhor forma de integração dos limites do bairro e seu desenvolvimento urbanístico (HAMMARBY SJÖSTAD, 2014).

O objetivo do trabalho é compreender como minimizar o impacto ambiental das cidades a fim de torná-las mais sustentáveis e autossuficientes principalmente do ponto de vista energético, da não geração de resíduos e no uso da água. Para isso será tomado como referência o estudo de caso do bairro Hammarby Sjöstad, em Estocolmo. O objeto do artigo se concentra na análise das soluções sustentáveis empregadas no estudo de caso, notadamente nos três principais eixos: água, resíduos e energia.

\section{MATERIAL E MÉTODOS}

Para o desenvolvimento do trabalho e obtenção do objetivo estabelecido foram consideradas as análises quantitativas e qualitativas, sendo:

a) Análise quantitativa: através de visitas técnicas ao local, levantamento de campo, entrevistas com a empresa de coleta de resíduos sólidos (Envac) e coleta de dados no centro de informações ambientais do bairro (GlashusEtt);

b) Análise qualitativa: análise das soluções sustentáveis empregadas no bairro através de dados oficiais, legislação e bibliografia específica como artigos, teses e livros publicados.

Após a consolidação dos dados primários coletados durante a visita técnica com a bibliografia específica serão finalmente discutidos e apresentados os resultados e conclusões do 
artigo. O bairro Hammarby Sjöstad é um modelo a ser considerado no planejamento, nas intervenções, urbanizações e construções de cidades e bairros ao redor do planeta. É um local que integra soluções ambientais eficientes e trabalha as políticas públicas de forma holística

\subsection{Um modelo internacional de bairro sustentável - Hammarby Model}

É possível observar no planejamento urbano das cidades suecas, principalmente nas grandes cidades como Estocolmo, Göteborg e Malmö, que a ocupação dos térreos dos edifícios é dedicada aos usos comerciais e de serviços enquanto que os andares superiores são reservados às habitações e também escritórios.

As cidades suecas se configuram como sendo predominantemente de uso misto, diminuindo o uso de serviços e comércios nos miolos das quadras e áreas mais periféricas. O uso misto propicia também a circulação de pessoas em diferentes horários trazendo movimento às ruas e aos bairros. No caso de Estocolmo as avenidas principais dos bairros abrigam grande variedade de restaurantes, cafés e bares que ficam abertos até de madrugada, além de lojas, supermercados, farmácias e outros comércios que variam os horários de funcionamento.

Em relação a Estocolmo, as calçadas das avenidas principais são largas com áreas verdes e mobiliários urbanos como bancos, jardins e outros. Há ciclovias exclusivas nas avenidas e ruas mais movimentadas e faixa para ônibus ou bonde. Nas ruas mais antigas de paralelepípedo, as calçadas são mais estreitas, mas ainda assim são acessíveis para pedestres e cadeirantes. Foi observado, nas cidades suecas, a intensa valorização pelo transporte público, por bicicleta e a pé, de forma que um habitante ou visitante facilmente possa se deslocar pela cidade.

Todos os sistemas se conectam e o cidadão pode utilizar o bilhete periódico que garante viagens ilimitadas em todo o sistema de transporte público num período específico. As linhas de metrô e trem conectam os bairros periféricos mais distantes da região metropolitana. Quanto ao transporte individual, o sueco deve pensar muito se vale a pena se deslocar até o local de trabalho e estudo com seu carro, pois os estacionamentos são poucos e caros, quase não há vagas nas ruas e as que existem são cobradas, há diversas ruas que o acesso é só para pedestre e bicicleta, outras o transporte coletivo e a ciclovia ocupam quase toda a largura da via, restando uma ou duas faixas para os automóveis e, como agravante, há ainda pedágio para transporte individual nas áreas centrais.

O bairro de Hammarby Sjöstad, em Estocolmo contrasta com a parte antiga da cidade, chamada de Gamla Stan (em português, Cidade Velha), cujas ruas são de paralelepípedos e muito estreitas, sendo possível acessá-las somente a pé ou de bicicleta. Nesta parte da cidade não é possível o acesso por automóvel ou ônibus, esses circulam por um anel que contorna a pequena ilha de Gamla Stan, onde ficam também os acessos ao metrô. No bairro novo os edifícios são recuados, sendo possível caminhar entre eles passando pelas áreas verdes e de lazer. Na figura 1 é possível observar a localização da Gamla Stan, embrião de Estocolmo, as demais ilhas que formam a cidade e o bairro novo.

Hoje, o bairro abriga mais de 26.000 habitantes em 11.500 unidades habitacionais e mais 36.000 munícipes que trabalham na região. O bairro possui toda a infraestrutura necessária como escolas, creches e centros de saúde. Aos poucos o comércio tem se diversificado e ampliado, recebendo diferentes segmentos além dos supermercados, farmácias, restaurantes e cafés locais (HAMMARBY SJÖSTAD, 2014).

O bairro é formado por edifícios modernos, praticamente do mesmo gabarito de altura, com algumas exceções. Muitos têm varandas e áreas envidraçadas para permitir a insolação e aquecimento nos dias iluminados. Não há muros ou cercas dividindo os lotes e as áreas públicas são compartilhadas entre os edifícios por paisagismo, áreas de lazer e estar. Há bancos, decks, mesas e playgrounds para as crianças nos miolos das quadras. $\mathrm{O}$ povo sueco valoriza muito os espaços públicos e as atividades ao ar livre, aproveitando intensamente os dias de calor e de luz. Portanto, o 
bairro novo promove ainda mais espaços públicos e áreas verdes que os demais bairros da cidade, todo o espaço entre as construções e a infraestrutura urbana é cuidadosamente aproveitado e integrado.

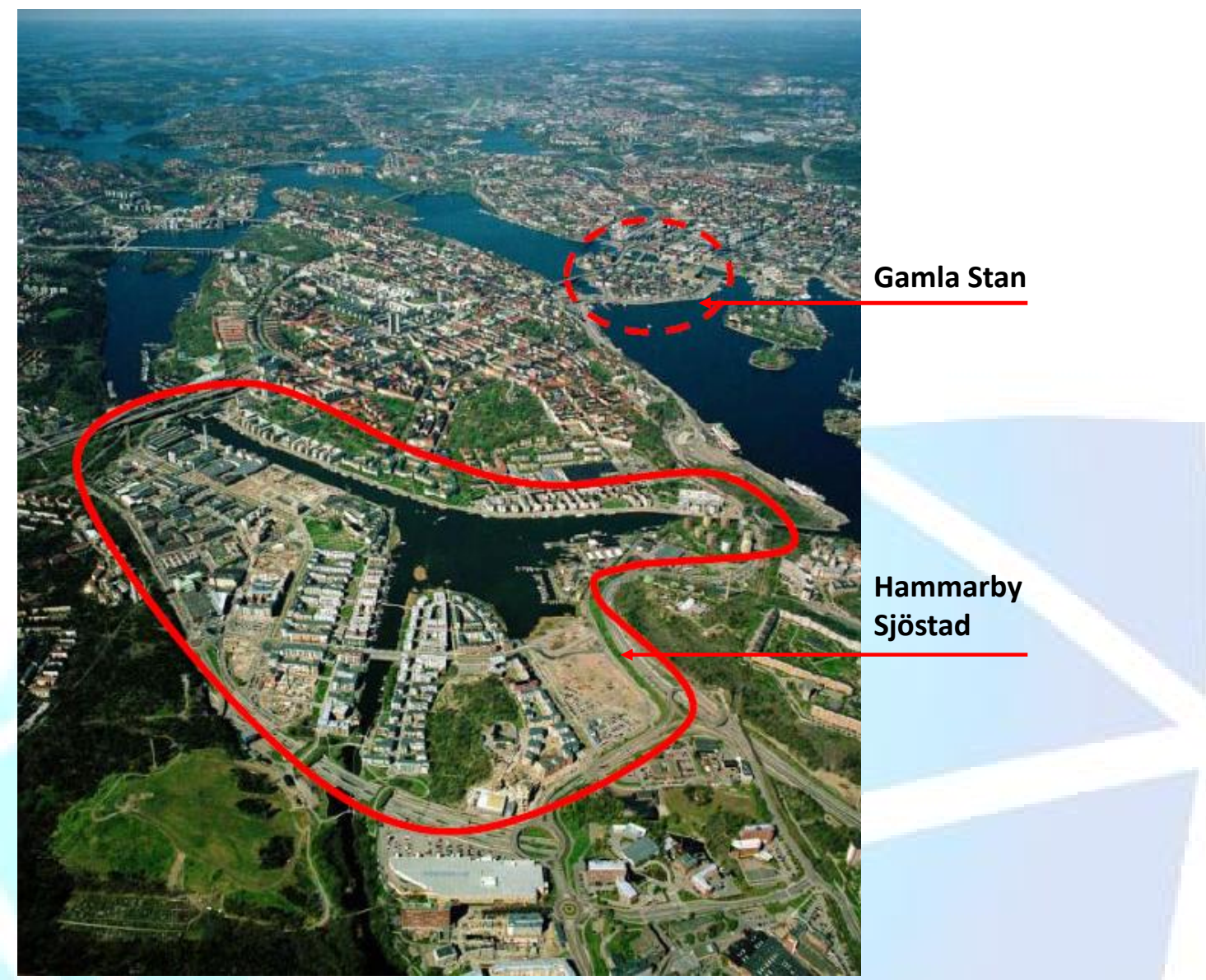

Figura 1. Mapa de Estocolmo e localização do bairro Hammarby Sjöstad. Fonte: FREUDENTHAL, 2010.

Cercado por canais que deságuam no lago principal, o bairro possui ainda áreas de deck e ancoragem para 100 pequenos barcos dos residentes no canal Sickla e está sendo construído um espaço para abrigar mais 80 barcos no canal Henrikdalshamnen. As áreas verdes e os canais constituem o coração do bairro tornando-o ainda mais atrativo e aumentando a qualidade de vida dos seus habitantes (HAMMARBY SJÖSTAD, 2014).

O bairro serviu de modelo para um conceito que foi desenvolvido depois, em conjunto com o governo e a iniciativa privada, chamado de Symbiocity, iniciado em 2008 com o objetivo de alcançar o desenvolvimento urbano de forma sustentável, exportando conhecimento e tecnologia para centros urbanos, principalmente em países em desenvolvimento. A diretriz principal é "conseguir mais com menos" por meio da integração dos diferentes setores que gerenciam uma determinada cidade. Por exemplo, o resíduo de uma indústria pode servir de matéria prima para outra, os rejeitos podem ser transformados em energia, o aquecimento excessivo de uma usina pode ser distribuído para as residências, a água de chuva pode ser coletada, tratada e utilizada, evitando enchentes e outras soluções que variam de um local para o outro.

O princípio consiste em aproveitar ao máximo a sinergia que existe naturalmente em um centro urbano, economizando recursos e minimizando o impacto ambiental. Para isso o conceito SymbioCity trabalha integrando 7 eixos principais: arquitetura; energia; paisagismo; tráfego e 
transporte; gerenciamento de resíduos; urbanismo, indústrias e edifícios; abastecimento de água e esgoto (ICLD e SKL, 2011).

Esse conjunto de soluções sustentáveis adotadas no bairro ficaram conhecidas como Hammarby Model, tratando-se de modelo que visa trabalhar em ciclo fechado, buscando a integração entre o sistema de transporte, de gestão de resíduos sólidos, de tratamento de água e eficiência energética. Atualmente, esse modelo é exportado para as cidades inteligentes (smart cities) como um modelo único de cooperação entre os principais setores: água, energia e resíduos (HAMMARBY SJÖSTAD, 2014).

O governo investiu intensamente na criação e manutenção dos espaços públicos do novo bairro, nos parques, na infraestrutura de transportes, como os bondes que conectam ao sistema de metrô e trens, como também no sistema fluvial por meio das balsas e barcos. As avenidas principais onde passam o sistema de transporte público são corredores verdes que interligam o bairro ao centro de Estocolmo e a cidade de Nacka ao sul. Além disso, o parque no sul do bairro conecta-se à maior reserva natural da cidade de Nacka.

Com o objetivo de impactar o mínimo possível a vegetação e flora nativas da região, foram construídos "ecodutos" em todo o anel viário, que são vias cobertas por vegetação para a passagem de animais e pedestres. A vegetação existente foi preservada e foram adicionadas novas áreas à reserva, que tem a intenção de atrair e manter animais, pássaros e insetos da região, além de proporcionar aos habitantes um local de contemplação e lazer (HAMMARBY SJÖSTAD, 2007).

A meta é que $80 \%$ das viagens no bairro sejam feitas a pé, ou de bicicleta ou de transporte público, portanto, a primeira medida tomada foi a remoção das barreiras impostas pela antiga ocupação industrial e a criação de um corredor para o transporte público, ciclovias e calçadas com locais para inserção de mobiliário urbano e paisagismo. O sistema de veículo leve sobre trilhos (tvärbanan) conecta o bairro ao sistema de metrô e trens. Trata-se do mesmo vagão que utiliza sistemas e velocidades diferentes de acordo com a sua localização. No bairro, os trilhos são integrados à paisagem, não constituindo uma barreira física e visual para os pedestres e o trem circula com velocidade inferior comparada ao metrô (Figura 2).
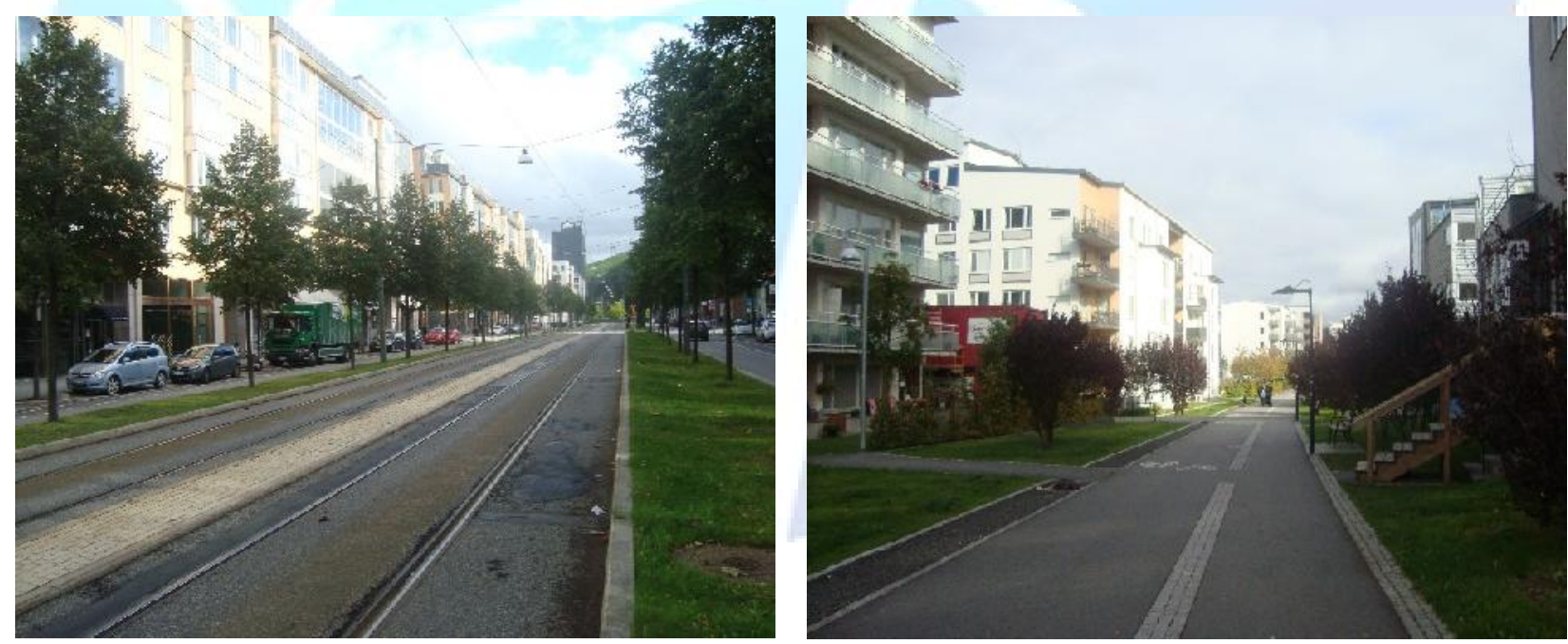

Figura 2. Fotos de Hammarby Sjöstad. Avenida principal com sistema de transporte público no centro. Rua interna para pedestres e bicicletas. Fonte: Autor, 2014.

Ao sair do bairro, o trem ganha velocidade e se conecta à rede de metrôs (tunnelbana) e trens (pendeltåg). Em relação ao transporte individual, foi implantado um sistema de compartilhamento de automóveis e, hoje, há 46 carros cadastrados para 910 usuários. Há também 
um local para carregamento de baterias de carros elétricos e também movidos a biogás (HAMMARBY SJÖSTAD, 2014).

Os materiais utilizados na construção dos edifícios são certificados, testados e sustentáveis, de forma a evitar que contenham substâncias nocivas ou produtos químicos que venham prejudicar o meio ambiente e a saúde dos moradores. Para as coberturas e fachadas dos edifícios foram utilizados materiais livres de metais pesados e de outras substâncias que pudessem prejudicar a qualidade da água de chuva recolhida e tratada localmente. Todas as construções passam por um rigoroso controle de materiais e recebem inspeções durante a obra.

Os construtores devem declarar os produtos e materiais utilizados de forma que o processo construtivo seja o menos impactante possível. Como diretrizes, o governo estabeleceu os seguintes critérios: madeiras tratadas com conservantes químicos foram banidas; é proibida a utilização de tubulações de cobre dentro e fora do edifício; materiais galvanizados devem receber tratamento na sua superfície externa; uso de recursos naturais deve ser minimizado, evitar o uso de extração de pedras e areia, incentivando a utilização de material reciclável e de reúso de outras construções e do próprio local; e materiais recicláveis podem e devem ser utilizados desde que sejam providenciados laudos técnicos provando sua resistência, eficiência e viabilidade econômica (HAMMARBY SJÖSTAD, 2007).

\subsection{Parâmetros sustentáveis adotados - resíduos, água e energia}

Uma das primeiras medidas tomadas, antes do início das construções, foi a descontaminação do solo de forma a garantir que nenhum ser vivo fosse posteriormente exposto a qualquer substância nociva. Para mencionar um exemplo, um dos trechos escavados (Sickla Udde) continha mais de 130 toneladas de óleos e graxas e ainda 180 toneladas de metais pesados, fruto das atividades industriais que ocorreram no passado (HAMMARBY SJÖSTAD, 2007). Esse autor tem como meta reduzir em 50\% o impacto ambiental provocado por novas construções desde a década de 1990, portanto, os edifícios construídos neste local necessitam ser 50\% mais eficientes que os seus antecedentes. Eficientes, principalmente, em relação ao uso dos recursos naturais, energia e água. Para atingir essas metas foram estabelecidos padrões de sustentabilidade nos edifícios e em toda a infraestrutura, incluindo o sistema de transporte.

Como critérios de sustentabilidade, a cidade de Estocolmo estabeleceu algumas diretrizes como por exemplo: mudanças no uso do solo, garantindo que o local fosse revitalizado, de uma área inóspita e abandonada para um local residencial agradável, com parques e muita área verde; o transporte deveria ser rápido, de fácil integração com os outros sistemas, com muitas ciclovias e calçadas, de forma a desestimular o uso de automóvel (Figura 2); os materiais utilizados nos edifícios deveriam ser locais, de baixo impacto e ambientalmente corretos. Para isso, foram utilizados materiais, como vidro, rochas locais, madeira e metais; a energia utilizada no bairro deveria ser proveniente de fontes renováveis como, biogás (extraído do esgoto e tratamento biológico de material orgânico), painéis solares e também da incineração dos rejeitos (waste-toenergy).

Estas fontes de energia deveriam ser combinadas com edifícios mais eficientes, que reduzissem o consumo energético; todo o esgoto e água deveriam ser tratados de forma mais eficiente possível, utilizando técnicas de reúso, aproveitamento de água pluvial e tratamento de águas cinzas e negras; os resíduos sólidos deveriam ser separados devidamente, tendo como prioridade a redução na origem, seguido do reúso, reciclagem e recuperação energética (HAMMARBY SJÖSTAD, 2007).

Em relação aos resíduos, o bairro segue as premissas de separação e destinação determinadas no Plano Municipal, que por sua vez, seguem o Plano Nacional e as legislações pertinentes, como o Código Ambiental (Miljöbalk) e a Lei dos Resíduos (Avfallsförordning). Portanto, os resíduos têm duas divisões principais que controlam sua coleta e destino, sendo: de 
responsabilidade municipal, as frações, orgânica, os rejeitos e os jornais e, de responsabilidade do produtor, embalagens recicláveis (papel, plástico, metal e vidro), eletroeletrônicos, e resíduos especiais (lâmpadas, baterias, pneus e outros).

O cidadão faz a separação dos resíduos em casa e leva cada tipo de resíduo até o local correto de armazenamento. Para as frações orgânicas, jornais e rejeitos há escotilhas da Envac (empresa responsável pela coleta à vácuo) na frente dos condomínios (Figura 3). No caso do orgânico, ele precisa estar livre de contaminantes para que o tratamento biológico seja eficiente. Por isso, cada unidade habitacional recebe uma chave para abrir a escotilha e sacos de papel para acondicionar esse material (Figura 3). A ideia da inserção da chave garante que somente material orgânico (restos de alimento) possa ser colocado neste local e o saco de papel não atrapalha o tratamento biológico como o saco de plástico.

De forma alguma, rejeitos e material não orgânico, podem ser misturados a esse resíduo, caso contrário todo o tratamento biológico via biodigestão anaeróbica ou compostagem será prejudicado. Em relação aos rejeitos, estes são encaminhados para o incinerador (waste-to-energy) que através da queima do material irá produzir energia e aquecimento para o bairro. Somente os rejeitos, material que não pode ser reutilizado, reciclado ou receber tratamento biológico pode ser encaminhado aos incineradores.
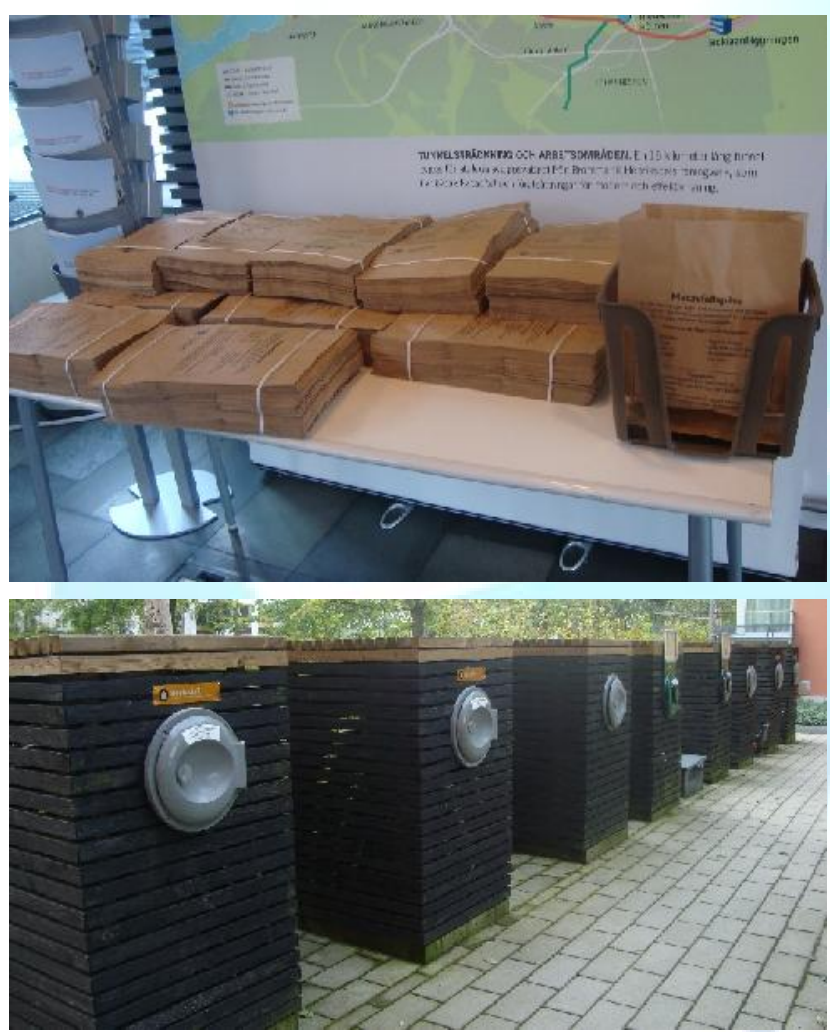

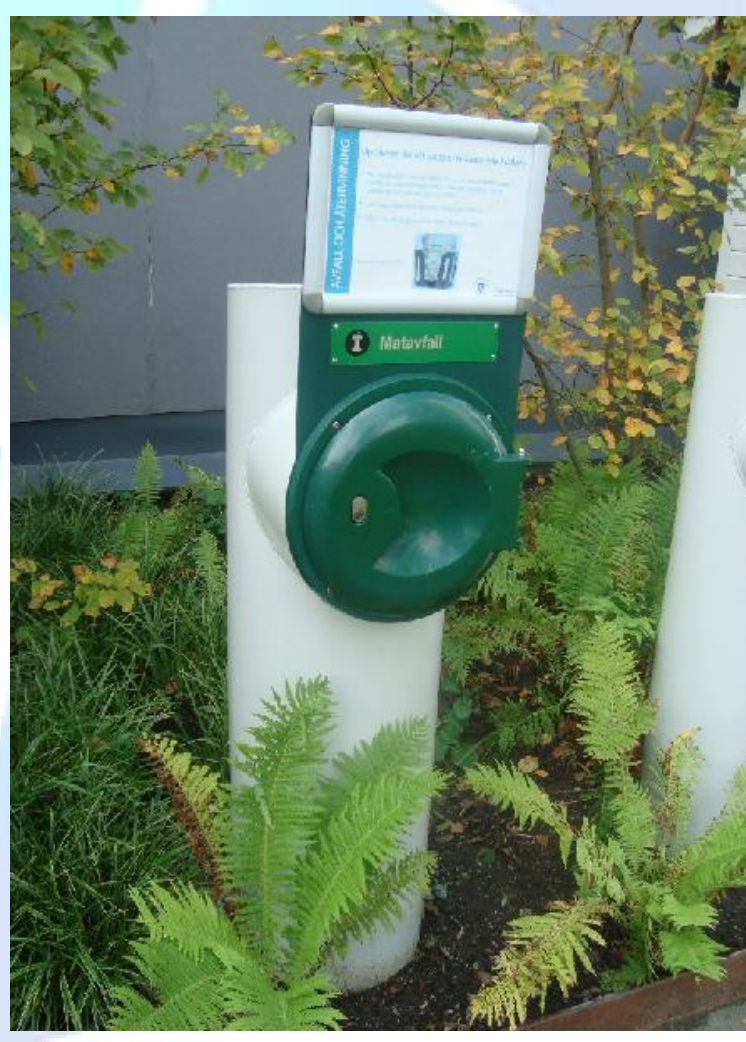

Figura 3. Saco de papel para resíduo orgânico; Escotilhas de material orgânico, rejeitos e jornais. Fonte: Autor, 2014.

Para as demais frações, o munícipe leva até a estação de reciclagem mais próxima, normalmente no térreo dos edifícios (na sua projeção ou em locais próximos à implantação). Estes locais são depósitos com containers separados para materiais recicláveis como: vidro incolor e colorido, metais (sucata, latas de aço, alumínio e outros), papéis e papelão (de embalagens em geral, revistas e impressos), plásticos (de embalagens em geral) e para materiais especiais, que normalmente ficam em um depósito separado: pilhas e baterias, lâmpadas fluorescentes, lâmpadas incandescentes, itens volumosos, como mobília em geral, brinquedos e outros, resíduos perigosos, 
como restos de tinta, vernizes, e eletroeletrônicos. Alguns itens, como medicamentos, outros resíduos perigosos como fertilizantes e agrotóxicos, pneus e outros, o cidadão deverá procurar o local adequado de descarte, normalmente no próprio local onde estes produtos são adquiridos, como supermercados, farmácias e lojas específicas ou nos centros de reciclagem e postos de entrega voluntária.

Para os resíduos de responsabilidade municipal, a empresa Envac realiza a coleta pneumática de duas formas: sistema estacionário e sistema móvel. Uma parte do bairro possui instalado o sistema móvel que destina os resíduos aspirados até um terminal ou para um sistema estacionário, onde os resíduos são encaminhados para containers que, ao atingirem sua capacidade, são substituídos por containers vazios ou, ainda, o conteúdo é aspirado para um caminhão container.

Para os resíduos de responsabilidade do produtor, as coletas variam de acordo com a demanda e o bairro, normalmente ocorrem quinzenalmente. Dessa forma, o resíduo é acumulado nos depósitos até a sua coleta e o munícipe é orientado a separar adequadamente nos containers cada tipo de material. Estes materiais devem estar limpos e secos e garrafas plásticas devem ser amassadas e caixas de leite e suco devem estar limpas e dobradas, essas atitudes ajudam a reduzir o volume das embalagens, aperfeiçoar o espaço e facilitar na coleta e transporte até os centros de reciclagem.

Em relação à eficiência energética, os edifícios passaram a ser cada vez mais eficientes, de forma a minimizar o consumo energético. Através de vidros duplos insulados e janelas vedadas é possível manter a temperatura interna agradável diminuindo a utilização do aquecimento. Graças ao isolamento ao redor das aberturas, as fachadas não perdem tanto calor como nos prédios mais antigos. As sacadas também ajudam, pois criam uma segunda fachada, protegendo ainda mais o interior. Parte da energia consumida no bairro é proveniente da incineração dos rejeitos (waste-toenergy) e parte do biogás é extraído do tratamento biológico da matéria orgânica e do esgoto. Através da incineração é possível também fornecer energia e aquecimento para o bairro (HAMMARBY SJÖSTAD, 2014).

Para o aquecimento do bairro são utilizadas várias fontes, sendo as duas principais o calor obtido na queima dos rejeitos no incinerador (waste-to-energy), conforme mencionado, e também o calor obtido no tratamento da água de esgoto. O restante do aquecimento, cerca de $15 \%$ é completado através de outras fontes como os biocombustíveis (WENNERSTEN e SPITSYNA, 2011). O sistema de aquecimento das cidades suecas (fjärrvärme) funciona em sistema fechado. A tubulação de água quente passa pelas fornalhas dos incineradores (waste-to-energy) e alimenta todos os edifícios (residências, hospitais, escolas, escritórios e outros). A água sai dos incineradores com um temperatura de cerca de $80{ }^{\circ} \mathrm{C}$, podendo chegar a $100{ }^{\circ} \mathrm{C}$ quando a temperatura externa estiver muito baixa. A água retorna aos incineradores com temperatura média de $50{ }^{\circ} \mathrm{C}$ e é reaquecida, voltando a ser distribuída (AVFALL SVERIGE, 2008)

Sjöstad em sueco significa cidade do lago e não é por acaso que o bairro recebeu esse nome, o projeto tem como prioridade principal a eficiência no uso da água. Portanto, várias técnicas de tratamento, aproveitamento e reúso são utilizadas no local. A água pluvial das ruas é coletada e tratada localmente. A água pluvial dos telhados é encaminhada para os canais onde também recebem tratamento, e deságuam nos lagos do local. A água servida e o esgoto também são coletados e tratados (HAMMARBY SJÖSTAD, 2014).

O esgoto dos edifícios é coletado e enviado para a estação de tratamento afastada do bairro, onde o mesmo é separado em duas frações, lodo e água, recebendo tratamentos distintos. Nesta estação, o primeiro é transformado em biogás, que é utilizado como combustível no transporte público e também distribuído na rede pública para abastecimento dos fogões das residências. O solo que sobra do lodo pode ser utilizado no cobrimento de escória da mineração e também em fazendas. A água do esgoto também é tratada e o calor utilizado no seu tratamento é reaproveitado no sistema 
de aquecimento central distribuído a todos os edifícios. Quanto menos resíduos tóxicos forem lançados no esgoto melhor será o seu tratamento (WENNERSTEN e SPITSYNA, 2011).

Para diminuir o consumo de água foram instalados no bairro sistemas hidráulicos mais eficientes, como arejadores nas torneiras e chuveiros, máquinas de lavar que utilizam menos água nas lavanderias compartilhadas, sistema duplo de descarga nos vasos sanitários e outros dispositivos que colaboraram na redução de $1 / 4$ do consumo de água de um edifício sem esses recursos. Em relação a água pluvial, foram adotados telhados verdes em alguns edifícios que auxiliam na diminuição das inundações. Toda a água pluvial captada dos telhados e das ruas é tratada localmente, assim como a água proveniente do derretimento da neve. O tratamento da água pluvial envolve primeiramente a remoção de sujeira e contaminantes superficiais. Na próxima etapa, a água é drenada para tanques onde permanecerá por horas para que o restante das partículas possam se acumular no fundo dos tanques por precipitação. Depois a água seguirá para filtros de areia e, por fim, para um sistema de filtragem biológico, conhecido como wetland e daí a água limpa segue para os canais e para os lagos (WENNERSTEN e SPITSYNA, 2011).

\section{RESULTADOS E DISCUSSÃO}

Importante mencionar que alguns dos itens planejados em relação aos 3 eixos (água, resíduos e energia) não foram plenamente executados, como por exemplo: os coletores solares para aquecimento de água a princípio seriam implantados em grande parte dos edifícios, mas foram instalados somente em alguns. Esse sistema estava planejado como auxiliar do sistema de aquecimento central, mas devido à existência de um sistema já em funcionamento somado à grande quantidade de resíduos combustíveis (rejeitos) que são encaminhados para o incinerador (waste-toenergy) para gerar eletricidade e aquecimento foram fatores determinantes que impediram a instalação dos aquecedores auxiliares.

Os painéis fotovoltaicos foram instalados somente em alguns edifícios devido ao alto custo da instalação, especialmente na década de 1990; e os trituradores de alimentos nas pias também não foram instalados durante a construção dos edifícios. A princípio, estes não foram instalados por uma série de razões, por acreditar-se que iria sobrecarregar o tratamento do esgoto, pelo custo do sistema e por legislações da época que impediam o uso do aparelho. No começo dos anos 2000, no entanto, a falta de biogás para abastecimento de veículos provocou uma crise no sistema energético de Estocolmo. Essa crise impulsionou um grupo de estudos a testar em 1000 residências o triturador. Houve um aumento na produção do biogás devido ao tratamento do esgoto, produzindo mais combustível e energia que prevaleceu frente ao receio do sobrecarregamento do sistema de tratamento de esgoto. Hoje, a maioria das residências possui o triturador instalado (IVEROTH et al., 2013).

Ainda assim, observa-se que o bairro Hammarby Sjöstad estabeleceu novo patamar em relação ao urbanismo e desenvolvimento sustentável. Hoje, é possível notar que parte dos critérios estabelecidos foram atingidos e servem de exemplos em outras cidades suecas. Bem como, a influência do bairro em conjunto com as ferramentas do conceito Symbiocity nas cidades de Malmö (Western Harbor) e Göteborg (Kvillebäcken), que também tiveram parte das suas áreas industriais e portuárias revitalizadas seguindo padrões sustentáveis. No sentido de exportar conhecimento e tecnologia sueca para outras cidades, o conceito Symbiocity estabelece parcerias com centros urbanos, principalmente de países em desenvolvimento, orientando sobre planejamento e desenvolvimento urbano sustentáveis e disponibilizando informações e tecnologia (SYMBIOCITY, 2014).

O centro de informações do bairro, GlashusEtt, é uma ferramenta fundamental, pois informa a população local como reduzir o consumo energético, como separar corretamente os resíduos em casa, a importância da utilização do transporte público e outras medidas. Esse equipamento é tão 
importante que os governos deveriam instalar um posto como esse em cada bairro, de forma que a sociedade realmente se envolvesse com as questões ambientais do local onde moram e aprendessem como reduzir sua pegada ecológica. Trata-se de um exemplo a ser seguido, pois reúne características essenciais de um bairro que é planejado, sustentável e ao mesmo tempo dinâmico.

Desde a integração com áreas verdes e públicas à eficiência e conforto dos seus edifícios, o zoneamento misto e o privilégio da mobilidade a pé, de bicicleta e transporte público, dentre outros aspectos. Todos esses e outros fatores contribuem para garantir a qualidade de vida dos seus habitantes e trabalhadores do local.

O desenvolvimento urbano sustentável traz benefícios desde a sua implantação e irá reduzir o consumo e uso de recursos naturais também a longo prazo. Portanto, os municípios deveriam avaliar essas questões durante o planejamento de um bairro novo ou a revitalização de uma área. Hammarby model, é um modelo que deveria ser considerado nos planejamentos e desenvolvimento urbano sustentáveis de bairros ao redor do mundo, principalmente em países em desenvolvimento.

\section{CONCLUSÕES}

O desenvolvimento de um bairro de forma holística, integrando diversos setores como, por exemplo, as empresas de água, energia e resíduos sólidos e mais o governo e profissionais diversos constituem uma maneira sustentável de se construir e modificar uma cidade. Por meio da integração dos sistemas e da busca por soluções conjuntas que minimizem o impacto ambiental é possível atingir as metas para um desenvolvimento sustentável, principalmente, no atual momento em que a humanidade se encontra, ações como essa são extremamente necessárias para reduzir a produção de gases de efeito estufa e, consequentemente, mitigar seus efeitos nas alterações climáticas.

O sucesso do bairro é devido também aos instrumentos econômicos implantados pela Suécia e as restritas regulamentações ambientais impostas não só pelo país mas também pela União Europeia. Esses dois fatores são visíveis em todas as cidades suecas e permitem que o desenvolvimento urbano ocorra de forma ambientalmente correta e, ainda assim, seja viável economicamente. O bairro, portanto, surgiu com esses dois fatores, mas ainda aglutinou novas ideias e tecnologias, de forma a superar os padrões existentes, sendo mais eficiente no uso da água, energia e gestão dos resíduos.

Para os seus habitantes e trabalhadores locais, o bairro traz qualidade de vida em vários aspectos, na integração com as áreas verdes e públicas, no zoneamento misto, na mobilidade eficiente e no respeito ao meio ambiente. Sem contar na eficiência dos edifícios que garantem conforto térmico, acústico e ainda economizam energia. Em relação à mobilidade, a integração com o sistema público de transporte é rápida e fácil, além disso há amplos passeios e ciclovias que incentivam o uso das bicicletas e a circulação a pé.

$\mathrm{O}$ uso de tecnologias mais avançadas no tratamento da água e equipamentos economizadores também são fatores decisivos para o sucesso do bairro. A coleta, tratamento e uso de água pluvial ajudam no combate às enchentes. Já os tratamentos da água cinza e negra garantem o fechamento do ciclo da água, reduzindo a poluição. O uso eficiente da energia através de edifícios mais modernos com sistema de isolamento que reduz o uso do aquecimento somado a aparelhos economizadores, lâmpadas e sensores que também reduzem o uso de eletricidade garante um impacto menor desses edifícios no consumo energético.

Em relação à gestão dos resíduos sólidos, a participação da população na separação dos resíduos na fonte constitui-se também em uma das fases mais importantes desse processo. Por isso, o governo junto com a iniciativa privada promovem constantes campanhas reforçando a importância desse hábito e as consequências para o meio ambiente e bem estar social da própria população. A responsabilidade é compartilhada por todos e cada um tem seu papel no modelo. Também a existência de um centro de informações como o GlashusEtt colabora muito com a 
divulgação das informações, acontecimentos e promoção da consciência ambiental dos moradores, visitantes e pessoas que trabalham e frequentam o bairro.

Concluindo, o desafio para os centros urbanos em todo o mundo é transformar seus distritos em bairros sustentáveis, utilizando como exemplo as técnicas empregadas no bairro Hammarby Sjöstad. Buscando soluções integradas que sejam mais eficientes do ponto de vista ambiental e ainda economicamente viáveis, que possam ser mantidas e atualizadas ao longo do tempo.

\section{REFERÊNCIAS}

AVFALL SVERIGE. Towards a greener future with Swedish waste-to-energy. The world's best example. 2008. Avfall Sverige, Swedish Waste Management. Disponível em: <www.avfallsverige.se/fileadmin/uploads/forbranning_eng.pdf>. Acesso em: 21 out. 2014.

FREUDENTHAL, E. Hammarby Sjöstad - unique environmental project in Stockholm. St. Peterburg, 2010. Skills for Sustainability: Capacity and Competencies for Practical Action for NGO-led SME Support Programs in Poland and North-West Russia. Disponível em: < http://www.ns.leontief-centre.ru/UserFiles/Files/ErikFruden.pdf>. Acesso em: 21 out. 2014.

HAMMARBY SJÖSTAD. A unique environmental Project in Stockholm. Stockholm: catálogo. Alfaprint, 2007. 40p.

HAMMARBY SJÖSTAD. Em ny stadsdel med vatten och miljö i fokus. [Em português: Um novo bairro com ênfase em água e ecologia]. Hammarby Sjöstad Ekonomisk Förening. 2011. Disponível em: <www.hammarbysjostad.se/miljo/pdf/HS\%20komb\%20sv\%20mars\%202011.pdf>. Acesso em: 29 set. 2014.

ICLD (Internationellt Centrum för Lokal Demokrati); SKL (Sveriges Kommuner och Landsting). Developing sustainable cities in Sweden. Stockholm: booklet. ICLD, SKL, 2011, 68p.

IVEROTH, S.P.; VERNAY, A.L.; MULDER, K.F.; BRANDT, N. Implications of systems integration at the urban level: the case of Hammarby Sjöstad, Stockholm. Journal of Cleaner Production, Tennessee, USA, n.48, p.220-231, 2013.

STOCKHOLM. Stockholm Stad. Stockholm i världen. 2010. Disponível em: www.stockholm.se>. Acesso em: 08 out. 2014.

SYMBIOCITY. Sustainability by Sweden. The Approach. 2010. Disponível em: <www.symbiocity.org>. Acesso em: 21 out. 2014.

WELLS W. Sweden, the Green Giant. A place where 'sustainability' means collaboration. Planning [serial online]. February, v.80, n.2: p.27-30, 2014; Available from: Business Source Complete, Ipswich, MA. Accessed October 10, 2014.

WENNERSTEN, R.; SPITSYNA, A. Environmental technology in a new urban neighborhood: Stockholm's Hammarby Sjöstad. In: What is Sustainable Technology?: Perceptions, Paradoxes and Possibilities, volume 1. UK: Greenleaf Publishing Limited, cap. 7, 2011, p.71-86. 